EESTI NSV TEADUSTE AKADEEMIA TOIMETISED. XVIII KOIDE

KEEMIA - GEOLOOGIA. 1969, Nr. 1

ИЗВЕСТИЯ АКАДЕМИИ НАУК ЭСТОНСКОН ССР. ТОМ ХVIII

Химия * ГЕология. 1969. N 1

\author{
Х. ВАХЕМЕТС, Л. СУНТ, Ф.ШЕМЯКИН
}

\title{
К ВОПРОСУ ОБ ОЧИСТКЕ СИЛЬНОКИСЛОТНОГО КАТИОНИТА С ПРИМЕНЕНИЕМ КОМПЛЕКСООБРАЗОВАНИЯ
}

Исследованы возможности глубокой очистки сильнокислотного катионита КУ-2 в натриевой форме с 0,15\%-ным (от емкости) начальным содержанием примесей железа (III) и меди (II) посредством применения 5-50 мM растворов ксмплексообразующих реактивов (комплексон III, тартрат натрия), а также растворов хлорида натрия.

Найдено, что устойчиьость образующегося комплекса определяет относительную глубину десорбции, минимальную концентращию лиганда и характер совместного действия хлорида натрия.

Введение в систему катионит-раствор ионов, способных связывать катионы в комплекс, смещает равновесие ионного обмена в результате замены этих катионов (частично или полностью) на новые частицы, отличающиеся от прежних либо по заряду, либо по сорбционной способности.

В литературе имеются данные об очистке ионитов при высокой и средней исходной степени наполнения с применением реакций комплексообразования [ $\left.{ }^{1-6}\right]$.

Ранее было показано, что умеренно разбавленные растворы тартрата натрия и комплексона III позволяют осуществить сравнительно глубокую очистку катионита КУ-2 в натриевой форме от ионов железа (III) и меди (II) (при малом исходном заполнении). Настоящее исследование является продолжением этой работы, но с более разбавленными растворами.

\section{Экспериментальная часть}

Подготовка ионита. Ионит КУ-2 с диаметром зерна $0,25-0,50$ мм кондицировали по способу, описанному в работе $\left[{ }^{7}\right]$. Основные характеристики очищенного катионита (полная и статическая обменная емкость, содержание воды и насыпной вес) определяли по обычной методике $\left[{ }^{8}\right]$. Содержание железа (III) определяли $о$-фенантролиновым методом $\left[{ }^{9}\right]$, а меди (II) - с помощью хлороформенного раствора диэтилдитиокарбамината свинца $[10,11]$. Измерения производились на фотоэлектрическом колориметре ФЭК-М-56.

Ошибка определения меди (II) не превышала 0,2 мкг и железа (III) $-0,7$ мка.

Для опытов по регенерации был приготовлен образец ионита в натриевой форме с содержанием железа (III) $5,1 \cdot 10^{-3}$ мг.экв/2 и меди (II) $1,8 \cdot 10^{-3}$ ме эквіг $\left(1,13 \cdot 10^{-1}\right.$ и $4,12 \cdot 10^{-2} \%$ от полной обменной емкости ионита соответственно).

Методика опытов по десорбции примесей. $\mathrm{K} 5$ мл влажного ионита $(2,72$ г на абсолютно сухой ионит) в конической колбе объемом 100 м приливали 50 мл регенерирующего раствора и выдерживали в течение 
суток при умеренном периодическом перемешивании. Контрольными опытами было установлено, что увеличение длительности контакта ионита с раствором до семи суток не смещает результаты за пределы воспроизводимости.

Равновесные концентрации примесей металлов определяли в обеих фазах изучаемых систем. Количество десорбированной примеси определяли из аликвотной части равновесного раствора. Оставшуюся в фазе ионита примесь десорбировали раствором специально очищенной соляной кислоты " и затем смесью хлорида натрия (х. ч.) и тартрата натрия (ч. д. а.). По количеству десорбированной примеси устанавливали равновесную концентрацию ее в ионите. Прочные комплексы комплексона̀ III (ч. д. а.) предварительно разлагали смесью концентрированной серной кислоты (х. ч.) и $30 \%$-ной перекиси водорода.

Процент десорбции примесей из ионита вычисляли как средний из двух-трех параллельных определений.

Десорбция системами, содержащими комплексон III. В настоящей работе исследовалось действие 5-50 мM растворов комплексона III и влияние присутствия 0,144 моль/л хлорида натрия на десорбцию следовых количеств ионов железа (III) и меди (II) при $\mathrm{pH} 4-5$ [7]. Полученные данные приведены в табл. 1.

Таблица 1

\begin{tabular}{|c|c|c|c|}
\hline \multicolumn{2}{|c|}{ Молярность раствора } & \multicolumn{2}{|c|}{ Процент десорбции } \\
\hline $\begin{array}{l}\text { по комплек- } \\
\text { сону III }\end{array}$ & $\begin{array}{l}\text { по хлориду } \\
\text { натрия }\end{array}$ & $\begin{array}{c}\text { железа } \\
\text { (III) }\end{array}$ & $\begin{array}{c}\text { меди } \\
\text { (II) }\end{array}$ \\
\hline
\end{tabular}

$\begin{array}{lc}5 \cdot 10^{-3} & - \\ 1 \cdot 10^{-2} & - \\ 2 \cdot 10^{-2} & - \\ 5 \cdot 10^{-2} & - \\ 2 \cdot 10^{-2} & 1,44 \cdot 10^{-1} \\ - & 1,44 \cdot 10^{-1}\end{array}$

82
85
83
84
82
2

Как показывает табл. 1, изменение концентрации комплексона III в указанных пределах не приводит к значительному изменению процента десорбции ионов железа (III) и меди (II) и 5 ммоль/л комплексона III не являются нижним пределом, допускающим удаление примесей ионов железа (III) и меди (II) из ионита с таким же-результатом, каи и более концентрированные растворы. Следует отметить, что ионное отношение по каждой из примесей $\left(h_{i}\right)$ относительно ионов комплексообразующего вещества (комплексон III) сохранялось во всех опытах на весьма высоком уровне - от 54,4 для железа (III) и 100 для меди (II) в начальных условиях и до 322 и 1666 соответственно после наступления равновесия (в случае 5 мM растворов). Избыток комплексона III был, таким образом, уже в начальных условиях опытов достаточно большим [более чем 50-кратным для ионов железа (III) и 100-кратным для ионов меди (II)] и к моменту равновесия возрастал примерно на един порядок.

Из данных табл. 1 видно, что прибавление хлорида натрия до концентрации, превышающей концентрацию комплексона III более чем в семь раз, не вызывает заметного повышения процента десорбции рассматриваемых примесей. Десорбирующее действие хлорида натрия в отдельности не выдерживает в этих условиях никакого сравнения с комплексоном III.

Десорбция системами, содержащими тартрат натрия. Состав и заряд тартратных комплексов металлов весьма чувствительны к изменениям

* Соляную кислоту (х. ч.) очищали отгонкой газообразного хлористого водорода под действнем концентрированной серной кислоты (х. ч.) н раствореннем полученного газа в воде двойной перегонки. 
pH среды $\left[{ }^{12,13}\right]$. На основе этих данных, а также результатов наших экспериментов [ $\left.{ }^{7}\right]$ пределы рН от 5 до 6 можно считать оптимальными для опытов по десорбции примесей с помощью растворов, содержащих тартрат натрия. В дальнейших экспериментах это учитывалось.

Кривые 1 и 2 на рис. 1, изображающие процент десорбции как функцию молярности раствора тартрата натрия, показывают, что десорбция примесей резко падает при концентрациях ниже 50 м.моль/л и вряд ли существенно повышается при использовании растворов, содержащих более 90 ммоль/ $\Omega$ тартрата натрия. Достигнутый при этом эффект десорбции сравнивается по

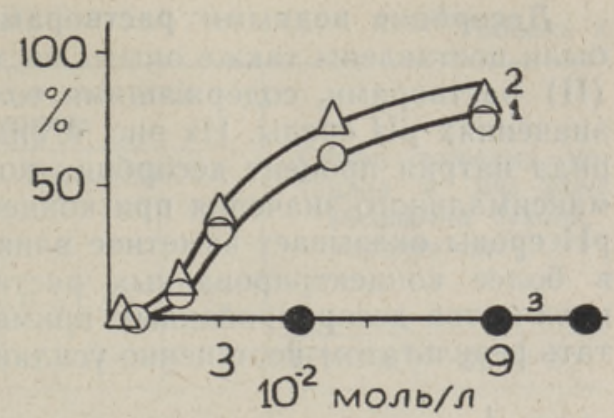

Рис. 1. Зависимость процента досорбции железа (III) и меди (II) от молярной концентрации тартрата натрия или хлорида натрня в регенернрующем растворе при $\mathrm{pH} \quad 5,5-6$ :

1 - железо (III) системой тартрат натриявода; 2 - медь (II) системой тартрат натрня-вода; 3 - железо (III) и медь (II) снстемой хлорид натрия-вода. хлориду натрия (кривая 3 на рис. 1).

Из рис. 2 и 3 , характеризующих влияние присутствия в регенерирующем растворе хлорида натрия, видно, что содержание 0,144 моль/ $\Omega$ хлорида натрия позволяет добиться почти максимального процента десорбции примесей, в особенности ионов железа (III), уже при концентрации тартрата натрия $1,2-2,0 \cdot 10^{-2}$ моль/л. Однако сама величина максимального процента десорбции остается относительно низкой: 60 $70 \%$ для железа (III) и $70-85 \%$ для меди (II).

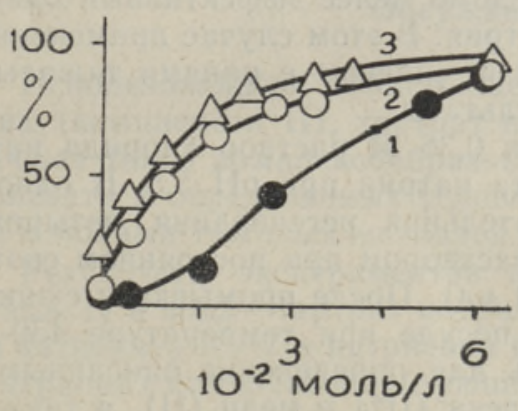

Рис. 2. Зависимость процента десорбции железа (III) от молярной концентрации тартрата в регенерирующей системе тартрат натрия-хло рид натрия-вода при $\mathrm{pH} 5,5$ :

Регенерирующне системы: $t$ - тартрат натрия-вода; 2 - тартрат натрня 0,144 моль/л хлорида натрия-вода: 3 тартрат натрня - 0.361 моль/л хлорида натрня-вода:

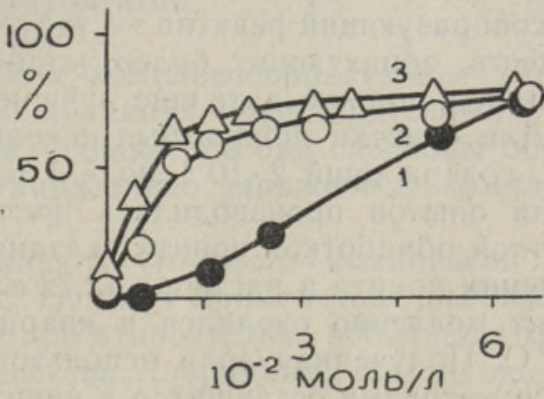

Рис. 3. Зависимость процента десорбции меди (II) от молярной концентрации в регенерирующей системе тар трат натрия-хлорид натрия-вода при $\mathrm{pH} 5,5$ :

Условные обозначения см. на рис. 2.

Приведенные данные позволяют заключить, что влияние хлорида натрия сравнительно велико лишь при низких концентрациях тартрата натрия ( $\leqslant 15$ ммоль/л) и довольно быстро уменьшается с ростом концентрации тартрата. Следовательно, существует некоторая оптимальная концентрация тартрата натрия, при которой добавление хлорида натрия оказывается нанболее эффективным. 
Десорбция водными растворами хлорида натрия. Для сравнения были поставлены также опыты по десорбции ионов железа (III) и меди (II) растворами, содержащими только хлорид натрия, при различных значениях рН среды. Из рис. 4 видно, что с ростом концентрации хлорида натрия процент десорбции ионов примеси возрастает и достигает максимального значения при концентрациях 1,8-2,0 моль/л. Изменение $\mathrm{pH}$ среды оказывает заметное влияние на процент десорбции, особенно в более концентрированных растворах $(C \geqslant 1$ моль/ $)$. Уменьшение количества десорбированных примесей с возрастанием $\mathrm{pH}$ можно считать результатом піостепенно усиливающегося гидролиза.

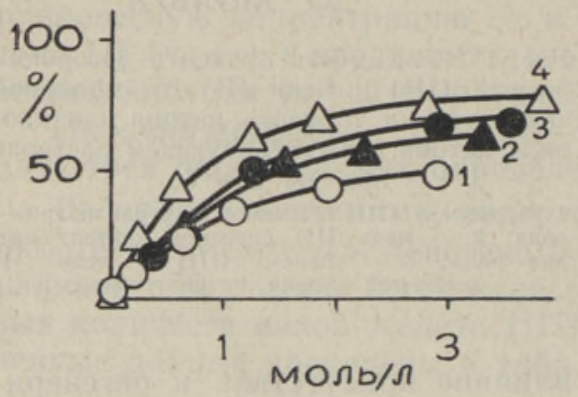

Pнс, 4. Зависимость процента десорбции нримесей от молярной концентрации и $\mathrm{pH}$ раствора хлорида натрия:

Десорбция железа (III): 1 - прн $\mathrm{pH} 7,0-7,5$; 3 - при рН 4,8-5,5. Десорбция меди (II): 2 при $\mathrm{pH} \quad 7,0-7,5 ; 4-$ при $\mathrm{pH} 4,8-5,5$.

Практически достижимая глубина очистки ионита с применением реакции комплексообразования. Представляет интерес проверка применимости рассмотренных систем для глубокой очистки ионита и, в частности, для оценки обоснованности применяемой нами методики кондицирования катионита.

В качестве добавки, способствующей десорбции ионов тяжелых металлов, целесообразно использовать заведомо менее эффективный комплексообразующий реактив - тартрат натрия. В этом случае применение веществ, образующих более устойчивые комплексы с ионами тяжелых металлов, должно дать еще лучшие результаты.

Для очистки ионита был использован $0,36 \mathrm{M}$ раствор хлорида натрия, содержащий $2 \cdot 10^{-2}$ моль/ $/$ тартрата натрия при $\mathrm{pH} 5,5$. В одной серии опытов производилась последовательная регенерация четырехкратной обработкой нонита указанным раствором при постоянном соотношении ионита и раствора $(2,72$ г на 50 мл). После промывки и сушки ионит медленно озолялся в кварцевой посуде при температуре 450 $500^{\circ} \mathrm{C}$. Полученная зола использовалась для определения описанными выше методами оставшихся в ионите железа (III) и меди (II), а также суммарного содержания тяжелых металлов по методике $\left[{ }^{14}\right]$. Аналогичным путем определялось содержание примесей в ионите, очистка которого производилась таким же раствором, но в динамических условиях, подробно описанных в $\left[{ }^{7}\right]$. Полученные результаты приведены в табл. 2 .

Зола очищенного в динамических условиях катионита была подвергнута качественному спектральному анализу с целью выяснения наличия в нем других примесей. Спектры снимались на спектрографе ИСП-28 при силе тока 6 и 15 а (время экспозиции - 30 сек., фотопластинки спектральные III). Примеси предварительно концентрировались на порошке спектрального угля упариванием хлороформенных растворов диэтилдитиокарбоминатов и 8-оксихинолятов, полученных обработкой этими растворами озоленного ионита соответственно при $\mathrm{pH} 4,7-4,8$ и 9,0-9,5 под инфракрасной лампой $\left[{ }^{15}\right]$. Результаты спектрального анализа показали, что, кроме железа и меди, в очищенном ионите содержатся в виде следов только алюминий, кремннй, кальций и титан. 
Таблица 2

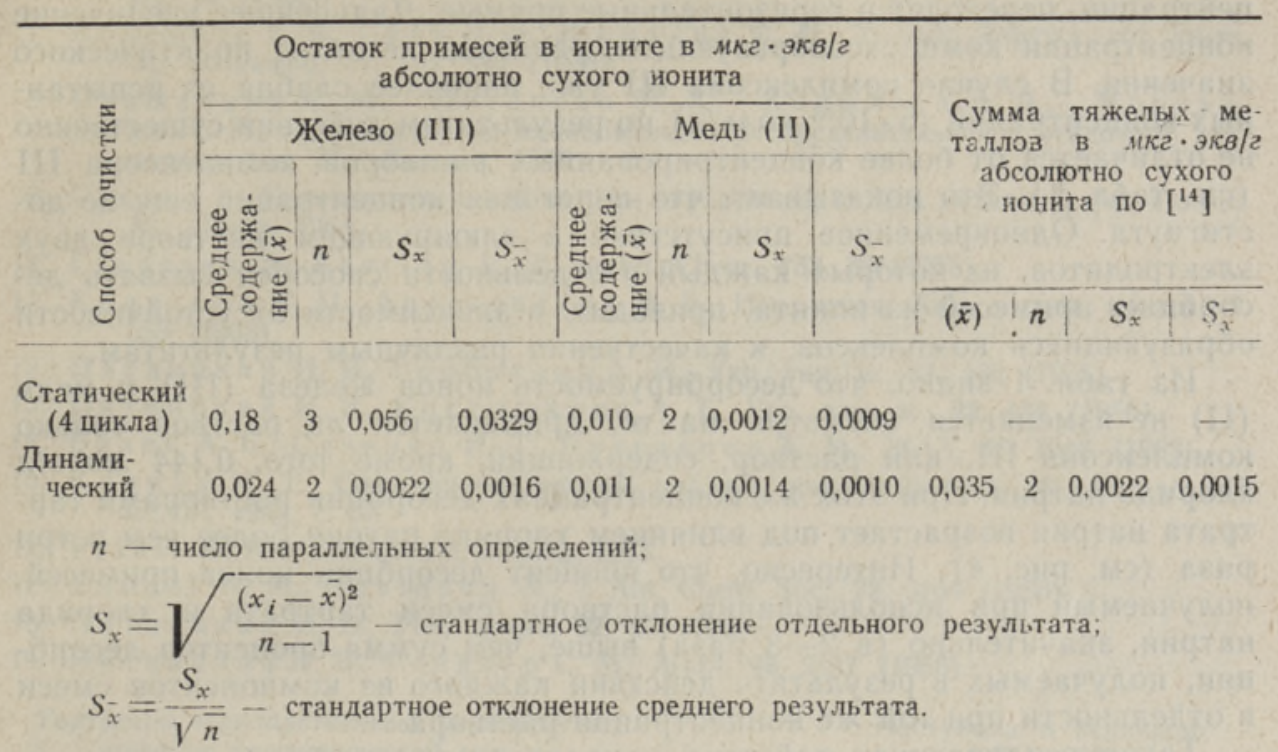

Полученные результаты позволяют утверждать что в случае тартратных систем возможна относительно глубокая регенерация ионита КУ-2 в натриевой форме как в статических условиях, путем повторения циклов (последовательной экстракции), так и в динамических условиях.

\section{Обсуждение результатов}

Использованные в настоящей работе комплексообразующие вещества (комплексон III, тартрат натрия) являются представителями различных типов комплексообразователей. Однако оба они способны образовывать в определенных условиях отрицательно заряженные комплексы с ионами тяжелых металлов.

Результаты экспериментов показывают, что вода-комплексон III (табл. 1) и вода-тартрат натрия (рис. 1) могут применяться для очистки катионита КУ-2 в натриевой форме при относительно небольших концентрациях комплексообразующего вещества. Хлоридные ионы не оказывают в аналогичных условиях существенного влияния на ионный обмен из-за неустойчивости образующихся комплексов. Отрицательно заряженные хлорокомплексы могут образовываться в заметных количествах только в более концентрированных растворах. Поэтому десорбция ионов железа (III) и меди (II) становится довольно большой при концентрашии $1,8-2,4$ моль/ $\Omega$ (рис. 4 ).

По достижимому проценту десорбции тартрат натрия уступает комплексону III всего на 5-8\%, но при этом требуется гораздо больший избыток реактива, чем в случае комплексона III,

Приведенные результаты согласуются с данными литературы $\left[{ }^{13}, 16-19\right]$ относительно различной устойчивости комплексов, образуемых рассматриваемыми лигандами с ионами железа (III) и меди (II): чем меньше устойчивость образуемого комплекса, тем больший избыток јеактива требуется для достижения максимальной десорбции и тем меньшим является вообще достижимый в результате однократного контакта процент десорбции. 
Кривые десорбции примесей, начиная с некоторой минимальной концентрации, переходят в горизонтальные прямые. Дальнейшее увеличение концентрации комплексообразующего реактива не имеет практического значения. В случае комплексона III уже наиболее слабая из испытанных концентраций $\left(5 \cdot 10^{-3}\right.$ моль/ $\left.\Omega\right)$ по результатам действия существенно не отличается от более концентрированных растворов комплексона III (см. табл. 1). Это показывает, что пороговая концентрация еще не достигнута. Одновременное присутствие в элюирующем растворе двух электролитов, из которых каждый в отдельности способен вызвать десорбцию примесей из ионита, приводит, в зависимости от устойчивости образующихся комплексов, к качественно различным результатам.

Из табл. 1 видно, что десорбируемость ионов железа (III) и меди (II) не изменяется, несмотря на то, применяется ли раствор только комплексона III, или раствор, содержащий, кроме того, 0,144 моль/ $\Omega$ хлорида натрия. При этих же концентрациях десорбщия растворами тартрата натрия возрастает под влиянием хлорида натрия более чем в три раза (см. рис. 4). Интересно, что процент десорбцин ионов примесей, получаемый при использовании раствора смеси тартрата и хлорида натрия, значительно (в 2-3 раза) выше, чем сумма процентов десорбции, получаемых в результате действия каждого из компонентов смеси в отдельности при той же концентрации раствора.

Такое усиливающее действие хлорида натрия наблюдается только в случае образования менее устойчивых комплексов типа тартратных и при сравнительно низкой концентрации комплексообразующего реактива.

B итоге можно утверждать, что при очистке катионита в натриевой форме от примесей ионов железа (III) и меди (II) определяющим фактором является устойчивость образуемых этими ионами комплексов с соответствующими реактивами. Это относится как к глубине десорбции примесей, к минимально необходимой концентрации комплексообразующего реактіва, так и к усиливающему действию хлорида натрия.

Наилучших результатов можно добиться, применяя сильноразбавленные растворы комплексона III $\left(5 \cdot 10^{-3}\right.$ моль/л и, по-видимому, даже меньше). Несколько менее эффективны смесь, содержащая 0,02 моль/ $\Omega$ тартрата натрия и около 0,1 моль/ $\Omega$ хлорида натрия, и $0,05 M$ водный раствор тартрата натрия.

Однако даже в лучшем случае в результате однократного контакта с раствором из ионита удается удалить до $80 \%$ ионов железа (III) и до $90 \%$ ионов меди (II). Для более полного удаления примесей из ионита необходимо повторить цикл десорбции или провести очистку в динамических условиях. На основании данных табл. 2 нетрудно убедиться, что при каждом следующем контакте ионита с раствором процент десорбции примеси несколько уменьшается, но тем не менее достаточно глубокая очистка ионита путем повторения циклов десорбции реальна.

\section{ЛИТЕРА Т У Р А}

1. Edge R. A., Chemist-Analyst, 47, 72 (1958).

2. Goren M. B., Ind. Engng Chem., 51, 539 (1959).

3. Л а а нпе ре Х. В., Ш емякин Ф. М., Изв. вузов, Хим. и хим. технол., 8, 768 (1965).

4. Л а а н пере Х. В., Уч. зап. Тартуск. гос. ун-та, Тр. по химни, НII, 3 (1966).

5 Лаанпере Х. В. Шемякин Ф. М., Уч. зап. Тартуск. гос. ун-та, Тр. по химии, III, 10 (1966). 
6. Л а ан пе ре Х. В., Ш е м якин Ф. М., Уq. зап. Тартуск. гос. ун-та, Тр. по химин, III, 19 (1966).

7. В ахеметс Х. Я., Суйт Л. Р., Шемякин Ф, М., Уч. зап. Тартуск. гос. ун-та, Tр. по хнмин, IV, 131, 142 (1968).

8. Ольшанова К. М., Потапова М. А., Копылова В. Д., Морозов а Н. М., Руководство по ионообменной, распределительной и осадочной хроматографин, М., «Химия», 1965.

9. С ендел Э., Колориметрические методы определения следов металлов, пер. с англ., M., «Мир», 1964.

10. C l a a s sen A., B a sting L., Z. analyt. Chem., 153, 30 (1956).

11. Қалинкин И. П., Алесковский В. Б., Изв. вузов, Хим. и хим. технол., 6 , 553 (1963).

12. П я тницкий И. В., Горб а тов а А. И., Укр. хнм. ж., 21, 182 (1955).

13. Пятницияй И. В., Костышкина А. Т., Укр. хнм. ж., 22, 434 (1956).

14. Бланк А. Б., Сизенко И. Т., Булгакова А. М., ЖАХ, 18, 1046 (1963).

15. Климов И. Т., Современные методы анализа прнродных вод, М., Изд-во АН CCCP, 1962 , с. 67.

16. Pribil R., Komplexometrie, Leipzig, 1963.

17. Connel H. M., Davidson N., J. Am. Chem. Soc., 72, 3164 (1950).

18. Пятницинй И. В., Усп, химин, 32,93 (1963).

19. П ятниций И. В., Гендлер С. М., ЖОХ, 26, 2137 (1956).

Тартуский государственный университет, кафедра неорганической хинии
Поступила в редакцию $1 / 1111968$

\section{H. VAHEMETS, L. SUIT, F. SEMJAKIN}

\section{KOMPLEKSIMOODUSTUMISE KASUTATAVUSEST TUGEVAHAPPELISE KATIONIIDI PUHASTAMISEL}

Uuriti tugevahappelise naatriumivormis kationiidi KU-2 sügavpuhastamise võimalusi komplekse moodustavate reaktiivide (kompleksoon III, naatriumtartraat, $5-50 \mathrm{mmool} / \mathrm{I}$ ) ja naatriumkloriidi lahuste abil raud(III) - ja vask(II) lisandeist, mille summaarne algsisaldus oli $0,15 \%$.

Leiti, et mpodustuvate komplekside püsivus määrab nii puhastuse sügavuse, lisandi minimaalse kontsentratsiooni kui ka naatriumkloriidi kaasmõju ulatuse.

\section{H. VAHEMETS, L. SUIT, F. SHEMYAKIN}

\section{ON PURIFICATION OF A STRONG ACID CATION EXCHANGE RESIN BY USING COMPLEX FORMATION}

The use of very dilute solutions of complexing agents as Trilone B and sodium tartrate has been investigated in order to make relatively deep purification of a strong acid cation exchange resin KU-2 (in sodium form) at a low degree of saturation ( 0.15 per cent) with iron (III) and copper (II).

It was found that the most important factor is the stability of the complexes formed, which has determined not only the percentage of desorption of these impurities but also their relative removal, the minimum concentration of the complexing agents in the regeneration solutions and the influence of the second electrolyte. 